Lecturer Kadriye ÖZYAZICI

Sivas Cumhuriyet University

Yildizeli Vocational High School

Department of Child Development

Assoc. Prof. Mehmet KANAK

Sivas Cumhuriyet University, Education Faculty

Department of Pre-School Education
Original scientific paper

UDC: 37.013 .42

DOI: $10.5937 /$ IstrPed20024760

\title{
THE RELATIONSHIP BETWEEN SOCIAL OSTRACISM AND FRIENDSHIP QUALITY AND FALSE IDENTITY IN SECONDARY SCHOOL STUDENTS
}

\begin{abstract}
Objectives: Adolescents endeavor to meet their social needs, to be accepted and to develop close friendship relationships. However, quality and close relationships may not always be possible.Identity development may be affected if adolescents cannot be included in social groups and cannot establish quality friendship relationships. This can be caused to false identity of adolescents who have not yet gained the ability to develop a original identity.

Methods: The study group consisted of three high schools, determined according to the entrance score of secondary education in Sivas city center and 510 students enrolled in secondary education with general aptitude exams in the 2017-2018 academic year. Social Exclusion Experiences Scale for Adolescents, False Identity Scale for Adolescents and Friendship Quality Scale were used as data collection tools.

Results: According to the regression analysis findings, it was observed that false self and acceptance variables predicted significant negligence, which is the subdimension of social exclusion variable. It significantly predicts the exclusion subdimension of the social exclusion variable of proximity and acceptance variables.

Conclusıon: The results of this study will contribute to adolescent identity development and will provide guidance to parents and teachers in order to establish a healthy friendship relations.
\end{abstract}

Key words: Social ostracism, friendship quality, false identity.

\section{Introduction}

Friendship is a relationship that starts in early childhood and develops in time (Yorukoglu, 2004). Friendship is a voluntary experience generally shared by a common relationship (Bukowski, Hoza, \& Boivin, 1993). It is clear from earlier researches that friendship is important at every age. Due to the developmental tasks of adolescence and its critical nature, friendship relationships have a special meaning. Intimate relationship with peers supports the developmental tasks that are undertaken in this period (Blackhart, Nelson, Knowles, \& Baumeister, 2009). In the beginning of the puberty period, young males and females can talk to their peers about the changes occurring in their bodies and their emotional problems, thus discovering themselves and their bodies (Kulaksizoglu, 2002). 
They spend most of their time with their parents in childhood, and this relationship can specifically be explained as the hierarchy of "inequalities". However, the relationship with their peers occurs as a result of the interaction between "equals". Relationship with peers offers the experience that cannot be provided by the relationship with parents. For this reason, the relationship with peers and friends in early adolescence creates one's first interpersonal relationships and contributes a lot to the emotional autonomy in young adolescence (Bukowski, Hoza, \& Boivin, 1993).

Ladd, Kochenderfer, \& Coleman (1996) state that the quality of the friendship is more important than the number of the friends in friendship relationships. This indicates that the expectation from a friendship is quality. The basics of a friendship relationship are its depth and quality (Akin, Karduz, \& Akin 2014). The notion of good friendship is subjective; so it is possible to face various qualities affecting friendship acceptance. Adolescents, young people and adults define good friendships as solidarity and commitment. Intimacy is an emotional source for individuals, and it is an educational body like an informal school (Thompson, Grace, \& Cohen, 2002). Friendship necessitates coherence (Bagwell, Newcomb, \& Bukowski, 1998), trust, confidence, sincerity, love, and support (Ladd, Kochenderfer, \& Coleman 1996). What defines the quality of a friendship is intimacy and sincerity. Intimacy, which can be described as depth, is generally one of the critical features of friendship. Revealing one's secret to a confidant is accepted as a descriptive feature of a relationship that is emotionally supportive (Kessler, Price, \& Wortman, 1985). Most people define their relationships with their friends as a "reciprocal" interaction, or rather shortly a "sacrifice/concession". There can be found social reciprocity in friendship relationships in almost all periods of life (Hartup \& Stevens, 1997).

The quality of a friendship is about peer acceptance (Parker \& Asher, 1993; Thien, Abd Razak, $\&$ Jamil, 2012). A strong quality friendship stems from the aspect of acceptance. That is why in literature, peer acceptance is a sign of friendship quality. Children become a member of groups due to their needs of friends, and there occurs complicated group dynamics. Children seek acceptance from the group even if at a minimum level. Sense of belonging and necessity of commitment, which are invisible natural powers, overwhelm all individuals in society. Unwritten rules of groups are in effect everywhere. Acceptance to groups, exclusion, and superior-subordinate relationships are social facts showing the hierarchy of groups (Thompson, Grace, \& Cohen, 2002). The need of belonging is often encountered in all areas and reflects a universal desire that provides gratification and a reciprocal interpersonal relationship. Belonging must be fulfilled to provide interpersonal comfort (Catanese \& Tice, 2005).

When individuals are not members of groups or when they give their importance up, they feel themselves mournful, lonely, and depressed, thus increasing their state of anxiety. Horney (1945) defines the source of "basic anxiety" as a feeling of "becoming isolated and desperate in a potentially hostile world". Both depression in general and social depression (dysphoria relating to the nature of the individual's social relationship) are inversely correlated with the degree of acceptance from one's circle. It is understood that apart from social relationships, belonging is an important aspect. Social contact alone is not enough to solve people's loneliness. There is no obvious difference in the time spent by those who are lonely and who are not (Baumeister \& Leary, 1995). Belonging to a group and the depth of relationships determine the degree of loneliness. 
Ostracism, which means being ignored or excluded by others, hinders a basic need in social relationships. When adolescents who are excluded are compared with those who can get in contact with social groups, it can be seen that excluded adolescents experience the feelings of depression, loneliness and inadequacy. The harmful effects of ostracism on psychology and social functionality are much more prevalent in adolescents compared to young children or adults (Gilman, Carter-Sowell, DeWall, Adams, \& Carboni, 2013).

It is assumed that adolescents modify their behaviours to get love and approval of their social circles, hence suppressing their real personality (Harter, Marold, Whitesell, \& Cobbs, 1996; Weir \& Jose, 2010). Adolescents start to separate their inner thoughts and feelings from their extrinsic self - the self that they exhibit to the outside world. Unnatural behaviours are shaped by adolescents' approval and perception. These behaviours are displayed as a result of the quality of the approval by their parents and peers. The conditioned support that they get from their circles directs them to develop a false identity. So, adolescents feel obliged to suppress their real identity to get the approval and acceptance of others. One's alienation from his/her real identity due to the lack of approval of others leads them to identity devaluation and exhibiting false behaviours (Harter, Marold, Whitesell, \& Cobbs, 1996).

Winnicott (1965) accepts that false identity is a matter of degree and that "normal" individuals use it as a means of adaptation. That means false identity appears when it is important to be socially coherent. When false identity is dominant in individuals' behaviours, it is a shield for real identity. However, the real self has a risk to disappear against false identity when it is not well-developed or is considered negative. Unnatural and inauthentic behaviours protect us from criticism and being rejected. It is considered that authentic behaviours pose a threat in making us defenceless against others' attacks in any circle. Together with that, when we are not understood by others, we think that we are misunderstood, we lose contact with our real identity and eventually life becomes meaningless. This is because others do not know who we are (Jourard, 1964). Self-concept develops and varies especially during adolescence, and this may lead to a prevalence in self-contradiction (Harter \& Monsour, 1992). Specifically, the behaviour of false self is defined as "ways not reflecting one's real identity" or "not being true to one's self". False identity is a set of faulty behaviours that do not reflect one's self in his/her behaviours. Clinically, in the literature, the phenomenon of false self is defined as alienation from the real sense of self-construal (Harter, Marold, Whitesell, \& Cobbs, 1996).

While adolescents endeavour to become socialized, they also search for identity. Friendship relationships, identity, and self are effectual terms for children and adolescents. Friendships function as a source for developing adolescents' identity and creating their self (Weir \& Jose, 2010). Adolescents try to meet their social needs, to be accepted, and to develop intimate friendship relationships. Nonetheless, having intimate and qualified relationships is not always possible. When adolescents are not part of a group and are not having qualified friendship relationships, their identity development might be affected. This may cause them to develop a false self as they are not able to develop an authentic identity. Accordingly, the research problem is that "Is there a significant relationship between secondary school students' social exclusion, friendship quality and their developing false identity?"

\section{Methods}

The design of the research, study group, data collection tool and statistical techniques in the analysis of the data are included under the methods. 


\section{The Research Design}

Predictive correlational design based on the relationship of dependent and independent variables is used in this research. In correlational researches, the purpose is to find out whether the variables change together, and how this change occurs, if it exists at all (Karasar, 2003). Predictive correlational research design is employed when the aim is to introduce indeterminate values belonging to a variable based on another variable referred as predictive (Cresswell, 2008). The aim of this study is to determine whether the dependent variable Social Ostracism (SO) predicts the False Self (FS) and Friendship Quality (FQ) variables and what the level of regression is.

\section{The Study Group}

In the study, maximum variation sampling method, which is one of the purposive sampling methods, is used. The reason for choosing this method was to acquire multiple data from as many participants as possible (Creswell, 2012). In the research, high schools representing different ranges of scores were selected. For that purpose, the schools were sorted out according to their entrance scores. The categorization of the samples were: schools with entrance scores of "401 and above", "those with entrance scores between 400 and 351", "those with entrance scores between 350 and 300", and schools accepting students according to a general aptitude test, and all were ministerial high schools of the Ministry of National Education in Sivas in the 2017-2018 academic year. One school was randomly selected for each category out of each score interval. The data was collected from 530 active high school students. The data of 16 students were left out due to being incomplete or incorrect, and 4 due to having extreme values. As a result, 510 participants were included in the study group. The high schools included in the study group were selected according to their entrance scores; then, random high schools were selected out of low, middle, and high score groups. Basic details relating to the study group is given in Table 1.

Table 1. Basic Details of the Study Group

\begin{tabular}{|c|c|c|c|}
\hline & Personal Information & $f$ & $\%$ \\
\hline \multirow{2}{*}{ Gender } & Female & 275 & 53,5 \\
\hline & Male & 239 & 46,5 \\
\hline \multirow{4}{*}{ School Base Score } & 455,292 base score & 133 & 25,9 \\
\hline & 350,972 base score & 152 & 29,6 \\
\hline & 370,221 base score & 156 & 30,4 \\
\hline & Aptitude Test & 73 & 14,2 \\
\hline \multicolumn{2}{|c|}{ Total } & 514 & 100,0 \\
\hline
\end{tabular}

According to Table 1, 53.5\% of the study group consisted of female students, while $46.5 \%$ consisted of male students. Gender distribution was balanced. In terms of schools' entrance scores, $25.9 \%$ of the group had an entrance score of $455.292,29.6 \%$ had $350.972,30.4 \%$ had 370.221 , and $14.2 \%$ were schools with an aptitude test. The distribution according to the scores was also balanced.

\section{Data Collection Tools}

The data were collected via the Social Exclusion, the Perception of False Self, and the Friendship Quality Scales. Below are the psychometric characteristics of the scales together with their convenience for the analysis of the data set. 


\section{Ostracism Experience Scale (OES)}

The Ostracism Experience Scale developed by Gilman et al. (2013) aims at evaluating individuals' exclusion from social groups or their being ignored on purpose and has been adapted to Turkish and reviewed for its validity and reliability by Akın, Dogan, Atik, Akin, Gonulalan, \& Cebis (2014). The scale has 11 items with two sub-dimensions (being ignored and exclusion). The scale has a 5-point Likert system ("1-Never", "2-Rarely", "3-Often", "4Usually", "5-Always"). There are inversely coded items in this scale. High scores in the scale show high level of social ostracism perception. The highest score in the scale is 55 points, and the lowest score is 11 points. As a result of the descriptive factor analysis to provide the construct validity of the scale, total variance was explained as $76.65 \%$, and factor load values were between .77 and .90 . The first sub-dimension of the scale (being ignored) has 5 items, and the second sub-dimension (exclusion) has 6 items. The factor loads of the items in the scale were between .71 and .88. The Cronbach Alpha internal consistency coefficient was .93 for the first sub-dimension, .90 for the second sub-dimension, and.89 for all items in the scale. The corrected item-test correlations of the scale were between .51 and .70 .

Confirmatory factor analysis on the data set was tested again by the researcher to recheck how consistent OES was with the data collected. The statistics of coherence on the data set after the analysis are given in summary in Table 2.

Table 2. OES Coherence Indices

\begin{tabular}{ll}
\hline Coherence Indices & Turkey \\
\hline $\mathbf{x}^{2} / \mathbf{s d}$ & 3.78 \\
\hline RMSEA & 0.07 \\
\hline GFI & 0.94 \\
\hline AGFI & 0.92 \\
\hline RMR & 0.05 \\
\hline NNFI & 0.96 \\
\hline CFI & 0.97 \\
\hline
\end{tabular}

As seen in Table 2, the design data coherence was perfect with a rate of $x^{2} / s d$ below 5 , a RMSEA value below .10, a RMR value below .10, and GFI, NNFI, CFI values above .90 (Thompson, 2000).

Besides, the Cronbach Alpha Internal Consistency coefficient of the scale was estimated as 0.82 for the "being ignored" sub-dimension and .86 for the "exclusion" sub-dimension.

\section{The Perception of False Self Scale (POFSS)}

The Perception False Self Scale developed by Weir and Jose (2010) aims at evaluating individuals' generalized self-perception when they feel it is faulty or false and has been adapted to Turkish and reviewed for its validity and reliability by Akin, Demirci, Yilmaz, \& Isik (2013). The scale is a measurement tool with 16 items and two sub-dimensions (False self and social anxiety). Items 1, 7, and 12 are inversely coded in the scale. The scale has a 5-point Likert rating system ("1-Strongly Disagree", "2-Disagree", "3-Neutral”, “4-Agree", "5-Strongly Agree"). High scores in the scale show that individuals' perception of false self is high. The highest score in the scale is 95 , and the lowest score is 16 . The general internal consistency coefficient of the scale was .75 , and the corrected item-test correlations of the scale were between .18 and .49. The factor loads of the items in the first sub-dimension (False self) explained $30.0 \%$ of the variance. The second sub-dimension (Social anxiety) had a positive correlation $(r=.47)$. 
Confirmatory factor analysis on the data set was tested again by the researcher to recheck how consistent POFSS was with the data collected. The statistics of coherence on the data set after the analysis are given in summary in Table 3.

Table 3. POFSS Coherence Indices

\begin{tabular}{lc}
\hline Coherence Indices & Values \\
\hline $\mathbf{x}^{2} / \mathbf{s d}$ & 3.77 \\
\hline RMSEA & .08 \\
\hline GFI & .91 \\
\hline IFI & .89 \\
\hline SRMR & .07 \\
\hline NNFI & .87 \\
\hline CFI & .89 \\
\hline
\end{tabular}

As seen in Table 2, the design data coherence was acceptable with a rate of $x^{2} / s d$ below 5 , a RMSEA value below .10, an SRMR value equal to .10, and IFI, GFI, NNFI, CFI values above .80 (Thompson, 2000). The Cronbach Alpha value of the POFSS was estimated as. 68.

\section{The Friendship Quality Scale (FQS)}

This scale was developed by Thien, Razak and Jamil (2012) and is used to examine the effects of friendship on individuals. The scale has been adopted to Turkish by Akin, Karduz, \& Akin (2014). The Friendship Quality Scale has 21 items with four sub-dimensions. It has a 5-point Likert rating system ("1-Strongly Disagree", "5-Strongly Agree”). The Friendship Quality Scale can be marked both for sub-dimensions and for the total. High scores show high levels of friendship quality. The first dimension of the scale (intimacy) has 6 items, the second (assistance) has 3 items, the third (acceptance) has 4 items, and the fourth (trust) has 8 items. Prior to the adaptation of the scale, the original internal consistency reliability coefficient was .83 for the first sub-dimension, .81 for the second sub-dimension, .84 for the third subdimension, and .88 for the fourth sub-dimension. After the adaptation of the scale to Turkish, the Cronbach Alpha internal consistency coefficient of the scale was .75 for the first subdimension, .81 for the second sub-dimension, .77 for the third sub-dimension, and .82 for the fourth sub-dimension; the total alpha value of the items in the scale was determined to be .91. The total item correlation coefficient of the scale was between .38 and .67 .

Confirmatory factor analysis on the data set has been rechecked by the researcher to find out how consistent FQS was with the data collected. The statistics of coherence as a result of the analysis of the data collected is given in Table 4.

Table 4. FQS Coherence Indices

\begin{tabular}{lc}
\hline Coherence Indices & Values \\
\hline $\mathbf{x}^{2} /$ sd & 2.44 \\
\hline RMSEA & .05 \\
\hline GFI & .92 \\
\hline AGFI & .90 \\
\hline SRMR & .04 \\
\hline NNFI & .97 \\
\hline CFI & .98 \\
\hline
\end{tabular}


As seen in Table 4, the design data coherence was good with a rate of $\mathrm{x}^{2} / \mathrm{sd}$ of 5 or below, a RMSEA value below .10, an SRMR value below .10, and GFI, AGFI, NNFI, CFI values above .90 (Thompson, 2000). The Cronbach Alpha values estimated for FQS was .80 for trust, .76 for the intimacy and acceptance, .81 for assistance, and .90 for the whole scale.

\section{Analysis of the Data}

The IBM SPSS 20 program was used to determine descriptive statistics and to examine the effect of regression considering the variables in the information form.

As the number of the independent variables was more than one, multiple regression analysis was made for the predictive effect. It is necessary for the variables to show normal distribution and to be continuous variables in the categorization scale in the case of the least exceptional equal interval in the regression analysis (Buyukozturk, 2005). Multiple regression analysis is used to measure whether a variable impacts other variables independently (Hoy, Tarter, \& Bliss, 1990).

\section{Multi-Variable Normality}

Multi-variable regression is used to predict parameters, and multi-variable normality regression, which is considered as the basic prediction technique, must be provided to use the maximum likelihood method. Multi-variable normality is a condition when all the variables and every linear combination of the variables are distributed normally (Tabachnick \& Fidel, 2007).

According to the result of the normality test on all the variables, the significance of Kolmogorov Smirnov values was under .05, but when skewness and kurtosis coefficients were taken into consideration, it showed a normal distribution due to being between +1 and -1 .

According to the matrix of scatter diagram, which is checked for testing bivariant normality hypothesis of the data, the variables had bivariant normal distribution.

Figure 1. Scatter Diagram by Bivariant Normality and Multi-Linear Tests

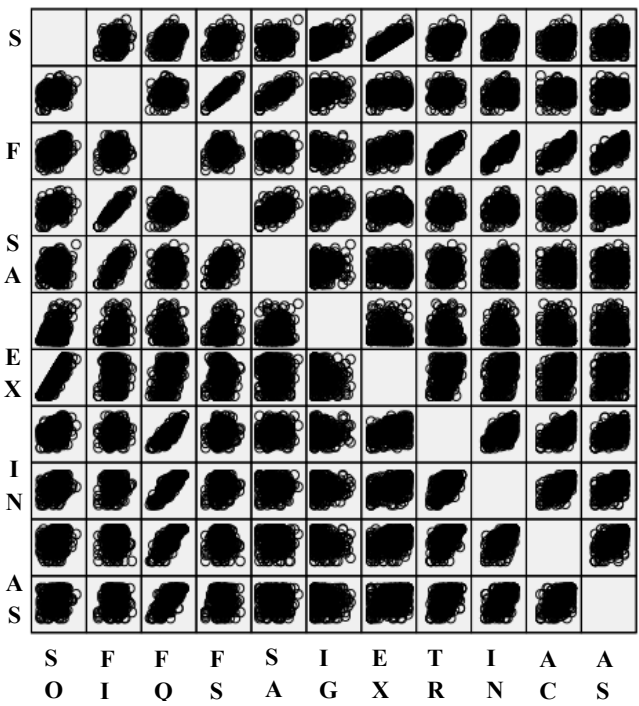




\section{Multicollinearity}

Linearity indicates linear relationship of the variables when the hypothesis of homogeneity equals to dependent variable or variables and shows that it is between predictor variables (Hair et al., 1992). Multicollinearity, on the other hand, represents the relationship between the linearity of dual variables. The scatter diagram in Figure 1 demonstrates the multicollinearity between the variables.

\section{Multiple Correlation}

Multiple correlation is a problem that emerges when the basic correlation coefficient between variables is above .85 in structural equation models (Kline, 2005). The biggest problem in case of multiple correlation between variables is predicting standard errors to be higher than they actually are. As high standard errors get minimized by a t value, type 2 error rate could increase (Pedhazur, 1997).

The most important and effective technique in revealing multiple correlation is to examine the correlation matrix of the predictors, coefficients, Variance Inflation Factor-VIF, and tolerance value (Cohen, Cohen, West, \& Aiken, 2003; Pedhazur, 1997). VIF is the indices that cause the inflation for the variation of each regression coefficient in case of variable not being correlated (Cohen, Cohen, West, \& Aiken, 2003). When the correlation level of the variable is the highest, VIF value is $\infty$; if there is no correlation, it is 1 . Tolerance value is the extent of independent explanation by a predictor on a variable out of other variables. When VIF value is 10 or above (VIF $\geq 10$ ), and tolerance value is .10 or below (Tolerans $\leq .10$ ), multiple correlation can be observed.

VIF and tolerance values of this study are given in Table 5 .

Table 5. VIF and Tolerance Coefficients of the Variables

\begin{tabular}{lrr}
\hline Variables & Tolerance & VIF \\
\hline FI &, 322 & 3,108 \\
\hline FS &, 700 & 1,428 \\
\hline SANX &, 751 & 1,331 \\
\hline SO &, 741 & 1,349 \\
\hline IGN &, 781 & 1,280 \\
\hline EXC &, 752 & 1,330 \\
\hline TRS &, 555 & 1,800 \\
\hline INTI &, 500 & 2,001 \\
\hline ACCP &, 464 & 2,154 \\
\hline ASSIS &, 560 & 1,785 \\
\hline
\end{tabular}

As seen in Table 5, there is a multiple correlation problem between variables according to VIF and Tolerance values.

\section{Results}

The findings in accordance with the objectives of this study are mentioned in this section, and they are then interpreted and discussed in light of the literature. 


\section{Regression Analysis Findings on the Being Ignored Sub-Dimension in Social Ostracism in Adolescents}

In Table 6, regression analysis findings are given on predicting the dependent variable "Social Ostracism-Being Ignored (IGN)" with reference to the independent variables designated for the study.

Table 6. Regression Analysis Findings on the Being lgnored Sub-Dimension in Social Ostracism

\begin{tabular}{|c|c|c|c|c|c|c|c|c|c|c|c|c|}
\hline \multicolumn{2}{|c|}{ Variables } & B & Std. Error & Beta & $t$ & $\mathrm{p}$ & Partial r & Dual $\mathbf{r}$ & $\mathbf{R}$ & $\mathbf{R}^{2}$ & $\mathbf{F}$ & p \\
\hline & Constant & 6.489 & 1.518 & & 4.275 & .000 & & & \multirow{7}{*}{.44} & \multirow{7}{*}{.18} & \multirow{7}{*}{10.855} & \multirow{7}{*}{.000} \\
\hline \multirow{2}{*}{$\mathrm{FI}$} & FS & .169 & .028 & .282 & 6.114 & $.000^{*}$ & .264 & .246 & & & & \\
\hline & SANX & .002 & .039 & .003 & .058 & .954 & .003 & .002 & & & & \\
\hline \multirow{4}{*}{ FQ } & TRS & .020 & .021 & .050 & .934 & .351 & .042 & .038 & & & & \\
\hline & INTI & .018 & .029 & .036 & .639 & .523 & .029 & .026 & & & & \\
\hline & ACCP & -.224 & .040 & -.318 & -5.594 & $.000 *$ & -.243 & -.225 & & & & \\
\hline & ASSIS & -.016 & .043 & -.020 & -.378 & .705 & -.017 & -.015 & & & & \\
\hline
\end{tabular}

As seen in Table 6, while the Being lgnored (IGN) sub-dimension of social ostracism variable was a significant predictor of the sub-dimension false self of False identity $(p<.05)$, social anxiety was irrelevant ( $p>05)$. As for the Friendship quality sub-dimension, only acceptance was significant $(p<.05)$. The dimensions trust, intimacy, and assistance were not significant predictors of the being ignored variable ( $p>05)$.

A fraction of change in the false self causes about .17 increase in being ignored. This means that individuals with false self are to face .17 fraction more for each range of change in being ignored by their circles. A fraction of change in the acceptance sub-dimension causes .22 range of decrease in the being Ignored. That is to say, the probability of ignored individuals to be accepted by their peers is lower. When Beta coefficients are considered, of these two variables, the variable "acceptance" (.318) was more effective than "false self" (.282).

The correlation coefficient between false self and being ignored was .25. There was a positive weak relationship between them. The more increase in false self, an average increase is found in being ignored. The correlation coefficient of false self with acceptance was -.22 . This means that individuals who are ignored get less acceptance by their peers. These two variables together explain $18 \%$ of being ignored. This means that, apart from the variables (false self, acceptance) examined and found to be significant in this study, other variables are also effective when ignored individuals face these behaviours. The regression equation of the study was; Being lgnored $=6.49+0.17^{*}$ False Self $-0.22 *$ Acceptance

\section{Regression Analysis Findings on the Exclusion Sub-Dimension in Social Ostracism in Adolescents}

In Table 7, regression analysis findings are given on predicting the dependent variable "Social Ostracism-Exclusion (EXC)" with reference to the independent variables designated for the study. 
Table 7. Regression Analysis Findings on Exclusion the Sub-Dimension in Social Ostracism

\begin{tabular}{|c|c|c|c|c|c|c|c|c|c|c|c|c|}
\hline Variables & & B & $\begin{array}{l}\text { Std. } \\
\text { Error }\end{array}$ & Beta & $t$ & $p$ & $\begin{array}{c}\text { Partial } \\
\mathbf{r}\end{array}$ & $\begin{array}{c}\text { Dual } \\
\mathbf{r}\end{array}$ & $\mathbf{R}$ & $\mathbf{R}^{2}$ & $\mathbf{F}$ & $\mathrm{p}$ \\
\hline & Constant & .667 & 2.876 & & .232 & .817 & & & \multirow{7}{*}{.47} & \multirow{7}{*}{.21} & \multirow{7}{*}{13.067} & \multirow{7}{*}{.000} \\
\hline \multirow[b]{2}{*}{ False Self } & FS & .052 & .052 & .045 & .988 & .324 & .044 & .039 & & & & \\
\hline & SANX & -.021 & .073 & -.013 & -.293 & .770 & -.013 & -.012 & & & & \\
\hline \multirow{4}{*}{$\begin{array}{c}\text { Friendship } \\
\text { Quality }\end{array}$} & TRS & .058 & .041 & .076 & 1.437 & .151 & .064 & .057 & & & & \\
\hline & INTI & .172 & .054 & .174 & 3.159 & $.002 *$ & .140 & .125 & & & & \\
\hline & ACCP & .290 & .076 & .213 & 3.820 & $.000^{*}$ & .169 & .151 & & & & \\
\hline & ASSIS & .093 & .082 & .060 & 1.137 & .256 & .051 & .045 & & & & \\
\hline
\end{tabular}

As seen in Table 7, the sub-dimension Exclusion (EXC) was a significant predictor of the intimacy sub-dimension and acceptance of friendship quality $(p<.05)$. The sub-dimensions trust and assistance were not significant predictors of the exclusion variable ( $p>.05)$. In short, the intimacy and acceptance variables were significant predictors of the Exclusion subdimension of social ostracism.

A fraction of change in the intimacy sub-dimension causes .17 positive increase in exclusion. In friendship quality, individuals showing intimacy face more exclusion. A similar result was obtained in the acceptance variable. A fraction of change in acceptance causes 29 increase in exclusion. When Beta coefficients were taken into consideration, it was observed that the order of importance of these variables were acceptance (.213) and false intimacy (.174).

The correlation coefficient of exclusion compared with intimacy was .13. The more intimacy increases, weaker so does exclusion. The correlation coefficient of exclusion compared with acceptance was .15 . That means excluded individuals get more acceptance by their peers.

These three variables together explained $20.17 \%$ of exclusion. The regression equivalence of the study was; Exclusion $=1.828+0.172 *$ Intimacy $+0.290 *$ Acceptance

\section{Discussion}

In this research, the relationship between Being Ignored (IGN), which is the sub-dimension of social ostracism, and Friendship quality and False self was studied.

It is observed that there is no significant relationship between the sub-dimensions of trust, intimacy, and assistance in friendship quality and being ignored. However, acceptance is a significant predictor of being ignored according to our research. Besides, while false self of false identity is a significant predictor, social anxiety is not a significant one. As acceptance increases, being ignored decreases; as false self increases, so does being ignored. The more adolescents get acceptance by their peers, less worrying becomes their perception on being ignored. Adolescents may alter their behaviours to get acceptance, especially during this period that has great importance in terms of friendship relationships and social circle. For this reason, to get more acceptance, they may modify their behaviours, and may even develop a false self. As they get acceptance by their peers, their perception of being ignored would become low.

As adolescents believe that they must behave in a certain pattern to get approval, not by reaching their objectives, they may consider that it is necessary to give a different account of 
themselves towards their social circle (Weir \& Jose, 2010). They can be motivated in showing themselves in a way that they get accepted by others. It is assumed that adolescents change their behaviours on purpose to get acceptance by others, hence suppressing their actual self. So, when adolescents are in a social environment with their peers, they may feel obliged to suppress their real self in order to get others' acceptance and to be noticed (Harter, Marold, Whitesell, \& Cobbs, 1996).

It is observed that intimacy and acceptance in friendship quality are significant predictors of exclusion, while trust and assistance are not. It is understood that the more intimacy increases, the weaker exclusion increases, and as acceptance increases, so does exclusion, albeit at a weak level. According to this result, the adolescent may be excluded by a group of friends but still may have a mutual friendship, or cannot have intimate relationships with group members in large group of friends. A large number of friends is not always an indicator of exclusion. In addition, adolescents who have a large number and group of friends may have more problems due to having more friendship relationships compared to those with less of such. Moreover, they may even face exclusion. Exclusion does not mean that adolescents do not have any friends, it is about the level of intimacy and acceptance.

Social ostracism does not always occur as a result of individuals' exclusion out of the group. Sometimes they may get accepted, even develop intimate friendships within their group of friends; however, this may not have an emotional importance in their group of peers. Individuals' not having a friendship is not necessarily a provider for a friendship relationship of good quality. Similarly, children who are rejected by their group of peers can also make friends (Bagwell, Newcomb, \& Bukowski, 1998).

It is observed that many children who get less acceptance by social groups have intimate friends (mutual friendships), and they are content with their friends. Kids who are isolated from social groups may be the favourite ones of some of their peers. Nevertheless, the friendship quality of these kids is mainly lower than others. Friendship quality affects group acceptance, possible loneliness, and having a friend at a different level (Parker \& Asher, 1993). Distinct social relationships are the best way to meet the needs of different periods of development. While the need of acceptance is provided by participating in a general peer group in middle childhood, it is characterized by interpersonal intimacy that emerges as a need in reaching puberty (Bagwell, Newcomb, \& Bukowski, 1998). The mutual friendship of adolescents cannot provide a group support or collective participation that social circles can provide. Groups provide special structural features such as transitivity, social stratification, and interdependence, which are beyond the features of mutual friendships. Even though close and intimate friendships become important to a child's development in puberty, it is believed that group identity and acceptance to a group has a central role in late childhood and early puberty (Witvliet, Brendgen, Van Lier, Koot, \& Vitaro, 2010). Sullivan (1913) claims that failure in having an intimate friendship in puberty results in feeling lonely. On account of this claim, the absence of supportive and intimate friendship may not be related to loneliness (Bagwell, Newcomb, \& Bukowski, 1998).

\section{Suggestions}

The suggestions for implementers and researchers as a result of the study conducted on high school students to identify their friendship quality, false self, and social ostracism in the 20172018 academic year are given below. 
Based on the findings of the research, the following suggestions may be put forward for researchers;

- Although this study casts light on some of the determinants of ostracism, different independent variables and study groups can be examined.

- The relationship between friendship quality, false self, and social ostracism can be studied using qualitative, mixed, and longitudinal research designs.

Based on the findings of the study, the following suggestions may be put forward for educators and program executives:

- One of the findings as a result of the research is that the more false self increases, the more frequent being ignored becomes, and ignored individuals are the ones who get less acceptance by their peers. With reference to that, it would be beneficial if teachers can take preventive and informative measures in their counselling sessions.

- Together with that, individuals showing a tendency to acceptance and intimacy face more exclusion. Teachers should observe their students closely and should have informative sessions on friendship relationships. Accordingly, educational scheme programmers should set programs that can develop friendship relationships and promote cooperative ones instead of competitive ones. Teachers should be attentive to create a class environment supporting bond of friendship in their educational activities. They may also organize out-of-school activities.

\section{NOTES:}

\section{Ethical Approval}

All procedures performed in studies involving human participants were in accordance with the ethical standards by the 1964 Helsinki declaration and its later amendments or comparable ethical standards.

\section{Informed Consent}

Informed consent was obtained from all individual participants included in the study.

\section{Conflict of Interest}

On behalf of all authors, the corresponding author states that there is no conflict of interest.

\section{References}

Akin, A., Karduz, F. F. A. \& Akin U. (2014). Arkadaslik kalitesi olcegi Turkce formunun gecerlik ve guvenirligi. Egitim ve Ogretim Arastirmalari Dergisi, 3(4), 378-383.

Bagwell, C. L., Newcomb, A. F., \& Bukowski, W. M. (1998). Preadolescent friendship and peer rejection as predictors of adult adjustment. Child development, 69(1), 140-153.

Baumeister, R. F., \& Leary, M. R. (1995). The need to belong: desire for interpersonal attachments as a fundamental human motivation. Psychological bulletin, 117(3), 497. 
Blackhart, G. C., Nelson, B. C., Knowles, M. L., \& Baumeister, R. F. (2009). Rejection elicits emotional reactions but neither causes immediate distress nor lowers self-esteem: $A$ meta-analytic review of 192 studies on social exclusion. Personality and Social Psychology Review, 13(4), 269-309.

Bukowski, W. M., Hoza, B., \& Boivin, M. (1993). Popularity, friendship, and emotional adjustment during early adolescence. New directions for child and adolescent development, (60), 23-37.

Buyukozturk, S. (2005). Sosyal Bilimler icin Veri Analizi El Kitabi. Ankara: Pegem Publishing.

Catanese, K. R., \& Tice, D. M. (2005). The effect of rejection on anti-social behaviors: Social exclusion produces aggressive behaviors. The social outcast: Ostracism, social exclusion, rejection, and bullying, 297-306.

Cohen, J., Cohen, P., West, S. G. \& Aiken, L. S. (2003). Applied multiple regression/correlation analysis for the behavioral sciences. Third edition. Mahwah, New Jersey: Lawrence Erlbaum Associates, Publishers.

Creswell, J. W. (2008). Educational research. Planing, conducting and evaluating qualitative and quantitative approaches. Pearson.

Creswell, J. W. (2012). Educational research. Planning, conducting, and evaluating quantitative and qualitative research. Pearson.

Gilman, R., Carter-Sowell, A., DeWall, C. N., Adams, R. E., \& Carboni, I. (2013). Validation of the ostracism experience scale for adolescents. Psychological assessment, 25(2), 319.

Hair, J. F., Black, W. C., Babin, B. J., \& Anderson, R. E. (2010). Multivariate data analysis: A global perspective (7. Baskı). Upper Saddle River, NJ: Pearson.

Harter, S. \& Monsour, A. (1992). Development analysis of conflict caused by opposing attributes in the adolescent self-portrait. Developmental Psychology, 28(2), 251.

Harter, S., Marold, D. B., Whitesell, N. R. \& Cobbs, G. (1996). A model of the effects of perceived parent and peer support on adolescent false self behavior. Child development, 67(2), 360-374.

Hartup, W. W., ve Stevens, N. (1997). Friendships and adaptation across the life span. Current directions in psychological science, 8(3), 76-79.

Horney, K. (1945). Our inner conflicts a cosntructive theory of neurosis. W. W. Norton.

Hoy, W. K., Tarter, J. C., ve Bliss. R. J. (1990). Organizational climate, school, health and effectiveness: A comparative analysis. Educational Administration Quarterly, (26)3, 260-279.

Jourard, S. M. (1964). The transparent self: Self-disclosure and well-being (No. 17). Princeton, $\mathrm{NJ}$ : Van Nostrand.

Karasar, N. (2003). Bilimsel Arastirma Yontemi. (12. Baskı). Ankara: Nobel Yayincilik.

Kessler, R. C, Price, R. H. ve Wortman, C. B. (1985). Social factors in psychopathology: Stress, social support, and coping processes. Annual Review of Psychology, 36, 531-572.

Kline, R. B., 2005. Principles and Practice of Structural Equation Modeling. New York: Guilford Press.

Kulaksizoglu, A. (2002). Ergenlik psikolojisi. Istanbul: Remzi Kitabevi.

Ladd, G. W., Kochenderfer, B. J. ve Coleman, C. C. (1996). Friendship quality as a apredictor of young chilren's early school adjustment. Chid Development, 67: 1103-1118.

Parker, J. G. ve Asher, S. R. (1993). Friendship and friendship quality in middle childhood: Links with peer group acceptance and feelings of loneliness and social dissatisfaction. Developmental Psychology, 29(4): 611- 621.

Pedhazur, E. J. (1997). Multiple Regression in Behavioral Research: Explanation and Prediction. Fort Worth, TX: Harcourt Brace College Publishers.

Sullivan, H. S. (Ed.). (2013). The interpersonal theory of psychiatry. Routledge. 
Tabachnick, B. G. ve Fidell, L. S. (1996). Using multivariate statistics (3 Ed.). New York: Harpercollins College Publishers.

Thien, L. M., Razak, N. A., \& Jamil, H. (2012). Friendship Quality Scale: Conceptualization, Development and Validation. Australian Association for Research in Education (NJ1).

Thompson, M., Grace, C. O., \& Cohen, L. J. (2002). Cocugunuzun arkadaslik iliskileri. E. N. Boylu (cev.). Arkadas Yayinlari, Ankara.

Weir, K. F., ve Jose, P. E. (2010). The perception of false self scale for adolescents: Reliability, validity, and longitudinal relationships with depressive and anxious symptoms. British Journal of Developmental Psychology, 28(2), 393-411.

Winnicott, D. W. (1965). The maturational processes and the facilitating environment: Studies in the theory of emotional development. International Universities Press.

Witvliet, M., Brendgen, M., Van Lier, P. A., Koot, H. M. ve Vitaro, F. (2010). Early adolescent depressive symptoms: Prediction from clique isolation, loneliness, and perceived social acceptance. Journal of abnormal child psychology, 38(8), 1045-1056.

Yorukoglu A. (1985). Genclik cagı, ruh sagligi egitimi ve ruhsal sorunlar. Ankara: Turkiye Is Bankasi Kultur Yayinlari Tisa Matbaasi, 277-282.

\section{Biographical notes:}

\section{Lecturer Kadriye Özyazıcı}

The author, who completed her undergraduate education in the Department of Preschool Teaching at Cumhuriyet University in 2007, completed her master's degree in 2018 at the educational sciences institute of the same university. She is still continuing Child Development doctorate education at İnönü University. The author, who worked as a teacher for 7 years after graduation, started her academic studies as a lecturer at Cumhuriyet University in 2016. Author's study topics; technology addiction, child development and pre-school education.

\section{Assoc. Prof. Mehmet KANAK}

Completed his bachelor's degree in preschool education at Cumhuriyet University in 2007, and master degree in preschool education at Inönü Unıversity in 2011 and PhD degree in child development and education at Gazi University in 2015. After two years of teaching experience at schools affiliated to the ministry of education, he began his academic studies as a lecturer at Hitit University in 2009. He started to work as a lecturer at Cumhuriyet University in 2013 and worked as an Assistant Professor between 2015-2019. Since 2019 he has been working as an Assoc. Prof. at the same university. He has studies in child abuse and neglect, preschool education, child development and teacher training 